\title{
Intermanual Differences in Movement-related Interhemispheric Inhibition
}

\author{
Julie Duque ${ }^{1,2}$, Nagako Murase ${ }^{1,3}$, Pablo Celnik ${ }^{1}$, \\ Friedhelm Hummel ${ }^{1}$, Michelle Harris-Love ${ }^{1}$, Riccardo Mazzocchio ${ }^{1,4}$, \\ Etienne Olivier ${ }^{2}$, and Leonardo G. Cohen ${ }^{1}$
}

\begin{abstract}
Interhemispheric inhibition (IHI) between motor cortical areas is thought to play a critical role in motor control and could influence manual dexterity. The purpose of this study was to investigate IHI preceding movements of the dominant and nondominant hands of healthy volunteers. Movement-related IHI was studied by means of a double-pulse transcranial magnetic stimulation protocol in right-handed individuals in a simple reaction time paradigm. IHI targeting the motor cortex contralateral $\left(\mathrm{IHI}_{\mathrm{C}}\right)$ and ipsilateral $\left(\mathrm{IHI}_{\mathrm{i}}\right)$ to each moving finger was determined. $\mathrm{IHI}_{\mathrm{c}}$ was comparable after the go signal, a long time preceding movement onset, in both hands. Closer to movement onset, $\mathrm{IHI}_{\mathrm{C}}$ reversed into facilitation for the right dominant hand but remained inhibitory
\end{abstract}

\section{INTRODUCTION}

Behavioral studies of manual dexterity have reported a superior proficiency of the right hand under a variety of motor conditions (Roy, Bryden, \& Cavill, 2003; Triggs, Calvanio, Levine, Heaton, \& Heilman, 2000; Triggs, Calvanio, \& Levine, 1997; Todor \& Kyprie, 1980; Peters \& Durding, 1978) in approximately $90 \%$ of the population (Coren \& Porac, 1977). However, the neural bases of these intermanual differences in motor control remain unclear.

One possibility is that this asymmetry in manual dexterity relates to differences in interhemispheric connectivity. Anatomical and physiological studies in animals (Aboitiz \& Montiel, 2003; Rouiller et al., 1994) and humans (Daskalakis, Christensen, Fitzgerald, Roshan, \& Chen, 2002; Di Lazzaro et al., 1999; Gerloff et al., 1998; Meyer, Roricht, \& Woiciechowsky, 1998; Thut et al., 1997; Meyer, Roricht, Grafin von Einsiedel, Kruggel, \& Weindl, 1995; Netz, Ziemann, \& Homberg, 1995; Ferbert et al., 1992) have documented interhemispheric interactions between both motor cortices. These interactions are predominantly inhibitory (interhemispheric inhibi-

\footnotetext{
${ }^{1}$ National Institutes of Health, ${ }^{2}$ Université catholique de Louvain,

${ }^{3}$ Tokushima University, ${ }^{4}$ Universitá di Siena
}

for left nondominant hand movements. $\mathrm{IHI}_{\mathrm{i}}$ displayed a nearly constant inhibition with a trough early in the premovement period in both hands. In conclusion, our results unveil a more important modulation of interhemispheric interactions during generation of dominant than nondominant hand movements. This modulation essentially consisted of a shift from a balanced IHI at rest to an IHI predominantly directed toward the ipsilateral primary motor cortex at movement onset. Such a mechanism might release muscles from inhibition in the contralateral primary motor cortex while preventing the occurrence of the mirror activity in ipsilateral primary motor cortex and could therefore contribute to intermanual differences in dexterity.

tion [IHI]) and can be studied by means of a doublepulse transcranial magnetic stimulation (TMS) protocol. The latter uses two magnetic stimulators to investigate the effect of a conditioning TMS pulse over one motor cortex on the amplitude of motor-evoked potentials (MEPs) elicited by another TMS pulse applied a few milliseconds later on the opposite motor cortex (Chen, 2004; Daskalakis et al., 2002; Ferbert et al., 1992). The strongest IHI is typically obtained when the conditioning stimulation (CS) precedes the test stimulation (TS) by about $10 \mathrm{msec}$. IHI is mediated predominantly through transcallosal connections (Daskalakis et al., 2002; Di Lazzaro et al., 1999; Meyer et al., 1995, 1998) with a probable subcortical contribution (Gerloff et al., 1998).

The view that asymmetries in hand motor control could relate to hemispheric differences in IHI has motivated human double-pulse TMS investigations comparing IHI from dominant-to-nondominant and from nondominantto-dominant hemispheres at rest (De Gennaro et al., 2004; Netz, 1999; Salerno \& Georgesco, 1996; Netz et al., 1995). Although some studies reported a stronger dominantto-nondominant hemisphere IHI (Netz, 1999; Netz et al., 1995), more detailed investigations testing a large range of CS-TS intervals and intensities revealed no differences (De Gennaro et al., 2004; Salerno \& Georgesco, 1996). 
One possible explanation for the lack of consistent evidence for brain asymmetries in IHI provided by these studies is that quantitative determinations of IHI tested at rest do not reflect IHI operating in association with performance of voluntary movements. Therefore, it is conceivable that evaluation of IHI in the process of generation of voluntary movements by either hand could provide additional insights on the contribution of IHI to intermanual asymmetries in dexterity.

We have previously shown that IHI targeting a motor cortex (M1) engaged in the preparation of a contralateral hand movement $\left(\mathrm{IHI}_{\mathrm{C}}\right)$ is profound immediately after the go signal in a reaction time (RT) paradigm (Duque, Hummel, et al., 2005; Murase, Duque, Mazzocchio, \& Cohen, 2004). As movement onset approaches, $\mathrm{IHI}_{\mathrm{C}}$ is released substantially (Duque, Hummel, et al., 2005; Murase et al., 2004). In contrast, IHI targeting the ipsilateral M1 $\left(\mathrm{IHI}_{\mathrm{i}}\right)$ remains deep throughout the movement preparation. Abnormalities in these inhibitory mechanisms correlate with the magnitude of motor impairment in the paretic hand of patients with chronic stroke (Murase et al., 2004), more prone to perform mirror movements (Kim et al., 2003). It is then possible that proper movement-related modulation of $\mathrm{IHI}_{\mathrm{C}}$ and $\mathrm{IHI}_{\mathrm{i}}$ may contribute to the ability of healthy subjects to perform unilateral finger motions without mirroring (Duque, Mazzocchio, et al., 2005; Swinnen, Dounskaia, \& Duysens, 2002; Leocani, Cohen, Wassermann, Ikoma, $\&$ Hallett, 2000).

Here, we used a standard double-pulse TMS protocol (Di Lazzaro et al., 1999; Gerloff et al., 1998; Meyer et al., 1998; Ferbert et al., 1992) to study movement-related modulation of $\mathrm{IHI}\left(\mathrm{IHI}_{\mathrm{C}}\right.$ and $\mathrm{IHI}_{\mathrm{i}}$ ) for right and left hand movements in right-handed individuals. We found a fundamental difference in the way IHI is modulated by movements of the dominant and nondominant hands.

\section{METHODS}

\section{Subjects}

Thirteen healthy right-handed individuals (Oldfield, 1971) participated in this study $(53 \pm 18.1$ years old; six women and seven men). All subjects gave their written informed consent, and the protocol was approved by the National Institute of Neurological Disorders and Stroke Institutional Review Board.

\section{Experimental Procedure}

Each subject sat in front of a computer screen and performed voluntary index finger movements with either the right or left hand. The task consisted of a simple RT paradigm in which they were instructed to perform index finger abduction motions as fast as possible in response to a go signal. After a short familiarization session, subjects participated in four separate sessions on different days (two for each hand, see below) in which IHI was tested using TMS at different time intervals preceding movement onset (Duque, Hummel, et al., 2005; Murase et al., 2004). Practice trials at the beginning of each session were used to characterize each individual's RT in the absence of TMS. RT was defined as the time between the go signal and the onset of the electromyographic (EMG) response (at the time when it first exceeded $100 \mu \mathrm{V}$ peak to peak). Surface EMG was recorded from the first dorsal interosseus (FDI) muscle of both hands in a time window that comprised $500 \mathrm{msec}$ before and $1000 \mathrm{msec}$ after the TS (see below). After amplification and bandpass filtering (50-2000 Hz) using a Counterpoint electromyography machine (Dantec Electronics, Skovlunde, Denmark), the signal was digitized (sampling rate $5000 \mathrm{~Hz}$ ) and stored on a personal computer for off-line analysis using a data acquisitionanalysis system written in LabView (Kaelin-Lang \& Cohen, 2000). To check whether the target muscles were at rest at the time of TMS for each trial, the EMG traces were inspected visually for $200 \mathrm{msec}$ preceding stimulation. Trials with background EMG activity exceeding $100 \mu \mathrm{V}$ in this 200-msec window were excluded from analysis.

\section{Measurement of Task-related Interhemispheric Inhibition}

The purpose of the study was to evaluate IHI relative to the onset of a voluntary movement in the two hands of healthy subjects. To that end, IHI was determined for each hand at 10 different timings in the RT period using a double-pulse paradigm previously described (Ferbert et al., 1992) (Figure 1A). The earliest IHI determination was always $30 \mathrm{msec}$ after the go signal, and the latest was at least 50 msec after the mean RT determined in unstimulated trials.

In double-pulse trials, the test TMS pulse (TS) applied to one M1 was preceded $10 \mathrm{msec}$ earlier by a conditioning TMS pulse (CS) delivered to the opposite M1 (Figure 1B) (Ferbert et al., 1992). Double-pulse trials $(\mathrm{CS}+\mathrm{TS})$ were randomly intermixed with those using TS alone. IHI was calculated for each timing by expressing the amplitude of the conditioned test MEPs in the double-pulse trials $\left[\mathrm{MEP}_{(\mathrm{CS}}+\mathrm{TS}\right), 10$ trials for each time point] relative to the amplitude of the unconditioned test MEPs when TS was delivered alone $\left[\mathrm{MEP}_{(\mathrm{TS})}, 10\right.$ trials at each time point]: $\left.\mathrm{IHI}=\mathrm{MEP}_{(\mathrm{CS}}+\mathrm{TS}\right) / \mathrm{MEP}_{(\mathrm{TS})}$ (Ferbert et al., 1992).

In this way, we measured $\mathrm{IHI}_{\mathrm{C}}$ (CS delivered to the motor cortex ipsilateral to the moving hand, iM1, and TS delivered to the motor cortex contralateral to the moving hand, cM1, Figure 1B, left), which conveys information on IHI from the ipsilateral to the contralateral M1, and $\mathrm{IHI}_{\mathrm{i}}$ (CS delivered to CM1 and TS delivered to iM1, Figure 1B, right), which conveys information on IHI from the contralateral to the ipsilateral $\mathrm{M} 1 . \mathrm{IHI}_{\mathrm{C}}$ and $\mathrm{IHI}_{\mathrm{i}}$ were tested for movements of the right $(n=11)$ and left $(n=11)$ 


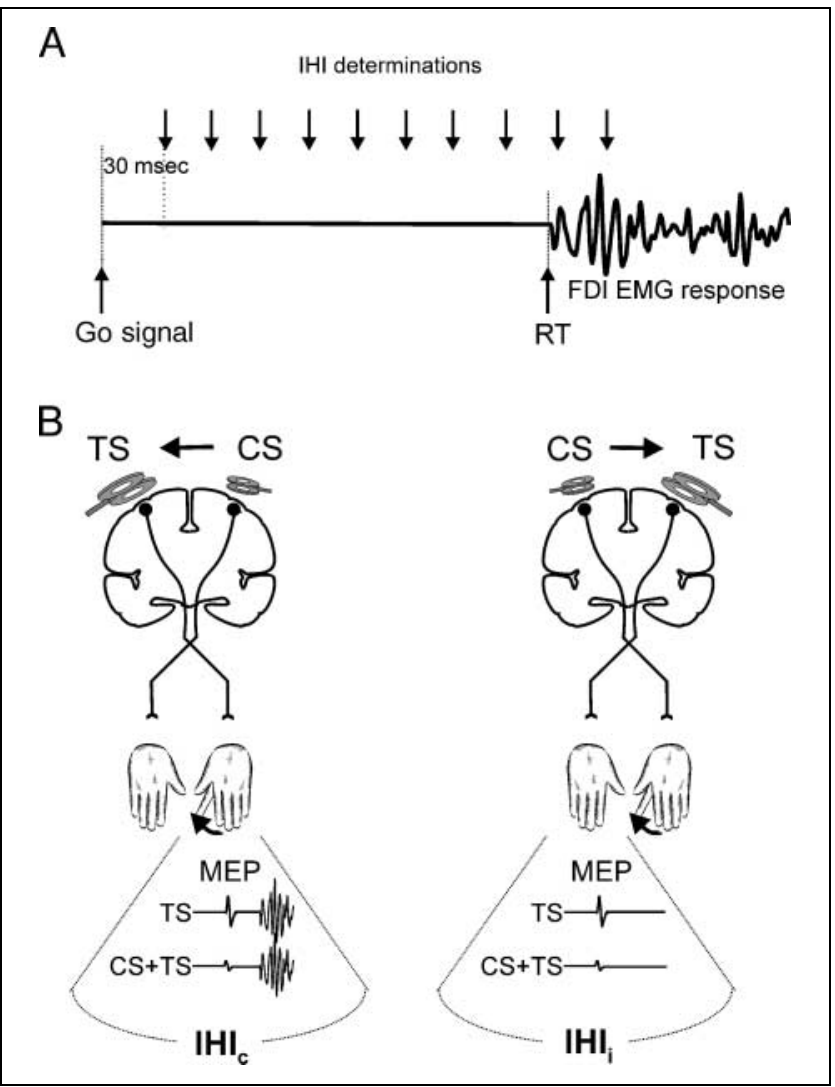

Figure 1. (A) IHI was evaluated in the process of generation of a voluntary movement by the right or left hand in a simple RT paradigm. Patients responded with a brisk index finger abduction motion to a go signal. The onset of the EMG response from the FDI muscle characterized the RT. IHI was determined at 10 different timings during the RT period. (B) $\mathrm{IHI}_{\mathrm{C}}$ (left) was studied by applying a CS to the iM1 (M1 ipsilateral to the moving hand) $10 \mathrm{msec}$ preceding a TS applied to the CM1 (M1 contralateral to the moving hand). $\mathrm{IHI}_{\mathrm{i}}$ (right) was studied by applying CS to the CM1 and TS to the iM1. $\mathrm{IHI}_{\mathrm{C}}$ and $\mathrm{IHI}_{\mathrm{i}}$ were each measured for movements of the right and left hands of subjects in a total of four separate sessions. See Methods for details on the size and orientation of CS and TS coils. IHI was expressed as the amplitude of the conditioned test MEPs $\left.\left[\mathrm{MEPs}_{(\mathrm{CS}}+\mathrm{TS}\right)\right]$ in the double-pulse trials relative to the amplitude of the unconditioned $\operatorname{MEPs}\left[\operatorname{MEPs}_{(\mathrm{TS})}\right]$ when TS was delivered alone for each IHI determination: $\left.\mathrm{MEP}_{(\mathrm{CS}}+\mathrm{TS}\right) / \mathrm{MEP}_{(\mathrm{TS})}$ (Ferbert et al., 1992).

hands of healthy subjects in four sessions on separate days. In most subjects, the right hand was tested before the left hand, but investigation of $\mathrm{IHI}_{\mathrm{C}}$ and $\mathrm{IHI}_{\mathrm{i}}$ was randomized in all subjects. Four subjects left the country before the end of the study and were only tested for their right $(n=2)$ or left hand $(n=2)$. As a result, statistical comparisons of IHI between the two hand movements were performed on 9 subjects.

\section{Transcranial Magnetic Stimulation}

TMS was delivered from two Magstim 200 magnetic stimulators (Magstim, Whitland, Dyfed, UK), each connected to a figure-eight coil. The coil for the TS (70-mm diameter) was placed tangentially over the M1 with the handle pointing backward and laterally at a $45^{\circ}$ angle away from the midline, approximately perpendicular to the central sulcus. The CS coil $(35-\mathrm{mm}$ internal diameter) was oriented at $90^{\circ}$ relative to the midsagittal line, a position thought to elicit predominantly D and I1 waves (Sakai et al., 1997; Schnitzler, Kessler, \& Benecke, 1996; Werhahn et al., 1994). The orientation and small size of the CS coil were chosen because, in most subjects, it was not possible to place two large size coils at $45^{\circ}$ to the midsagittal line. This setup enabled us to optimize baseline IHI determination in all subjects. The optimal scalp position for eliciting a contralateral MEP was identified and marked on a head cap placed on the patient's scalp. Resting motor threshold (rMT) was determined at this site and defined as the minimum stimulus intensity that produced MEPs $\geq 50 \mu \mathrm{V}$ peak to peak in at least 5 of 10 trials (Rossini et al., 1994).

For TS, we used the intensity of stimulation required to evoke MEP amplitudes of about 0.5 to $1.5 \mathrm{mV}$ at rest (Boroojerdi, Diefenbach, \& Ferbert, 1996; Ferbert et al., 1992), and for CS, we used the intensity required to evoke IHI of approximately $50 \%$ in double-pulse trials at rest (Murase et al., 2004). In this way, we ensured a comparable magnitude of IHI at rest in the four experimental sessions (see Results).

\section{Determination of Premovement Interhemispheric Inhibition}

To quantify IHI preceding movement onset, we used three measures (Duque, Hummel, et al., 2005; Murase et al., 2004): (a) maximum IHI ( $\mathrm{IHI}_{\max }$ ), defined as the maximal (deepest) IHI identified in a given individual in any of the timings falling at least $70 \mathrm{msec}$ after the go signal in the RT paradigm. We chose this delay $(70 \mathrm{msec})$ to make sure $\mathrm{IHI}_{\max }$ reflected processing within motor regions at a time they were most likely already involved in movement preparation. (b) IHI immediately before movement onset ( IHI $_{\text {bef-mvt }}$ ) was defined by identifying first the timings at which the TS fell after EMG onset in a proportion of up to $50 \%$ of the trials. We then included in the analysis only the trials in which TS fell before EMG onset at the defined intervals. Finally, the last variable was (c) IHI around movement onset ( $\mathrm{IHI}_{\text {mvt-onset }}$ ), defined as IHI determined at the timing immediately preceding (but at least $5 \mathrm{msec}$ before) the mean RT in unstimulated trials; all trials at that particular interval, including those where TMS fell after EMG onset, were considered for analysis. These three measures were computed for $\mathrm{IHI}_{\mathrm{C}}\left(\mathrm{IHI}_{\mathrm{C}} \max , \mathrm{IHI}_{\mathrm{C}}\right.$ bef-mvt, $\mathrm{IHI}_{\mathrm{C}}$ mvt-onset $)$ and $\mathrm{IHI}_{\mathrm{i}}\left(\mathrm{IHI}_{\mathrm{i}} \max , \mathrm{IHI}_{\mathrm{i}}\right.$ bef-mvt, $\mathrm{IHI}_{\mathrm{i}}$ mvt-onset $)$ for movements of the right and left hands of subjects.

To unveil a possible shift in the balance between the IHI exerted by each motor cortex concomitantly during movement preparation, we computed the difference between $\mathrm{IHI}_{\mathrm{i}}$ and $\mathrm{IHI}_{\mathrm{C}}$ at all timings $\left(\mathrm{IHI}_{\mathrm{i}}-\mathrm{c} \max , \mathrm{IHI}_{\mathrm{i}}-\right.$ c bef-mvt, $\mathrm{IHI}_{\mathrm{i}}-\mathrm{c}$ mvt-onset) for movements of the left and 
Table 1. CS and TS Intensities (Mean $\pm S D$ )

\begin{tabular}{|c|c|c|c|}
\hline & \multicolumn{2}{|c|}{ Moving Hand } & \multirow[b]{2}{*}{$\begin{array}{c}p \text { Value } \\
\text { (Right/Left) }\end{array}$} \\
\hline & $\begin{array}{l}\text { Right Hand } \\
(n=11)\end{array}$ & $\begin{array}{c}\text { Left Hand } \\
(n=11)\end{array}$ & \\
\hline \multicolumn{4}{|l|}{$I H I_{c}$} \\
\hline CS intensity (\% output) & $58.8 \pm 8.5$ & $57.6 \pm 10.9$ & $n s$ \\
\hline TS intensity (\% output) & $52.1 \pm 10.3$ & $49.9 \pm 10.7$ & $n s$ \\
\hline \multicolumn{4}{|l|}{$I H I_{i}$} \\
\hline CS intensity (\% output) & $57.6 \pm 12.2$ & $54.9 \pm 8.8$ & $n s$ \\
\hline TS intensity (\% output) & $49.6 \pm 9.8$ & $49.8 \pm 8.1$ & $n s$ \\
\hline
\end{tabular}

Four subjects were only tested for their left $(n=2)$ or right $(n=2)$ hand, and statistics are therefore reported for the nine subjects tested on both hands.

right hands. An index close to 0 would reveal comparable levels of $\mathrm{IHI}_{\mathrm{C}}$ and $\mathrm{IHI}_{\mathrm{i}}$ (balanced IHI); positive values $\left(\mathrm{IHI}_{\mathrm{i}} \gg \gg \mathrm{IHI}_{\mathrm{C}}\right)$ would reflect deeper $\mathrm{IHI}_{\mathrm{C}}$ than $\mathrm{IHI}_{\mathrm{i}}$, and negative values $\left(\mathrm{IHI}_{\mathrm{i}} \ll \ll \mathrm{IHI}_{\mathrm{C}}\right)$ would reflect deeper $\mathrm{IHI}_{\mathrm{i}}$ than $\mathrm{IHI}_{\mathrm{C}}$. As a consequence, a specific release in $\mathrm{IHI}_{\mathrm{C}}$ with respect to $\mathrm{IHI}_{\mathrm{i}}$ during movement preparation should result in a progressive decrease in $\mathrm{IHI}_{\mathrm{i}}-\mathrm{c}$.

\section{Statistical Analysis}

Log transformations were applied when data were not normally distributed (Kolmogorov-Smirnov tests). RTs and corticospinal excitability at rest were analyzed using one-way repeated measures analyses of variance (ANOVAs) with hand (left, right) as factor. Separate repeated measures ANOVAs with factors moving hand (left, right) and timing $\left(\mathrm{IHI}_{\text {rest }}, \mathrm{IHI}_{\mathrm{max}}, \mathrm{IHI}_{\text {bef-mvt }}, \mathrm{IHI}_{\text {mvt-onset }}\right.$ ) were used to analyze premovement IHI targeting the cM1 $\left(\mathrm{IHI}_{\mathrm{C}}\right)$ and $\mathrm{iM1}\left(\mathrm{IHI}_{\mathrm{i}}\right), \mathrm{IHI}_{\mathrm{i}-\mathrm{c}}$, and corresponding CS and TS MEP amplitudes. Post hoc pairwise comparisons were performed using Tukey and paired $t$ tests when required. Data are expressed as mean $\pm S D$. Because the age of subjects ranged from 27 to 79 years old, we could investigate the effect of age on premovement IHI by means of the Pearson correlation procedure. Part of these data has served as control for previous studies investigating the effect of IHI on motor function in elder patients with chronic stroke (Duque, Hummel, et al., 2005; Murase et al., 2004).

\section{RESULTS}

\section{Reaction Time, Corticospinal Excitability, and Interhemispheric Inhibition at Rest}

There was no significant difference between RTs for the left $(199 \pm 27.0 \mathrm{msec})$ and right hands (179 \pm $33.7 \mathrm{msec})$. In addition, the resting motor threshold was found comparable in the right $(43 \% \pm 5.9 \%)$ and left M1 $(44 \% \pm 6.9 \%)$. The intensity used for CS and TS was also similar for the two hand movement conditions (see Table 1; ANOVA, ns). Finally, as required by the experimental design (see Methods), the magnitude of $\mathrm{IHI}_{\text {rest }}$ was comparable across all sessions as well as were $\mathrm{MEP}_{(\mathrm{TS})}$ and $\mathrm{MEP}_{(\mathrm{CS})}$ amplitudes (Tables 2 and 3).

\section{Modulation of Interhemispheric Inhibition Targeting the Primary Motor Cortex Contralateral to the Moving Hand}

$\mathrm{IHI}_{\mathrm{C}}$ conveys information on the IHI originating in iM1 and targeting $\mathrm{CM} 1$, the motor cortex controlling the moving hand. $\mathrm{IHI}_{\mathrm{C}} \max , \mathrm{IHI}_{\mathrm{c}}$ bef-mvt, and $\mathrm{IHI}_{\mathrm{c}}$ mvt-onset were measured $97 \pm 20.9,160 \pm 28.3$, and $159 \pm 30.2 \mathrm{msec}$, respectively, after the go signal for movements of the right hand and $107 \pm 23.1,165 \pm 28.2,180 \pm 24.1 \mathrm{msec}$ for movements of the left hand (ANOVA, $n s$ ). When subjects performed right index finger abductions, $\mathrm{IHI}_{\mathrm{C}}$ was deep close to the go signal and changed into facilitation around movement onset (Figure 2). With left index finger abduction, $\mathrm{IHI}_{\mathrm{c}}$ was also deep close to the go signal but did not turn into facilitation at movement onset (Figure 2). This is shown by a significant main effect of timing $(F=13.7, p<.001)$ and a Significant Timing $\times$ Moving Hand interaction $(F=$ $5.4, p=.01)$. Although $\mathrm{IHI}_{\mathrm{c} \max }$ was comparable with

Table 2. IHI Targeting the cM1 (IHIc) and MEP Amplitudes of CS and TS (Mean $\pm S D$ )

\begin{tabular}{|c|c|c|c|}
\hline \multirow[b]{2}{*}{$\begin{array}{l}\operatorname{IHI}_{c}\left[M E P_{(C S}+T S\right) / \\
\left.M E P_{(T S)}\right]\end{array}$} & \multicolumn{2}{|c|}{ Moving Hand } & \multirow[b]{2}{*}{$\begin{array}{c}p \text { Value } \\
\text { (Right/Left) }\end{array}$} \\
\hline & $\begin{array}{l}\text { Right Hand } \\
(n=11)\end{array}$ & $\begin{array}{l}\text { Left Hand } \\
(n=11)\end{array}$ & \\
\hline$I H I_{c \text { rest }}(m V)$ & $0.63 \pm 0.16$ & $0.61 \pm 0.17$ & ns \\
\hline $\mathrm{MEP}_{(\mathrm{CS})}$ & $1.63 \pm 1.03$ & $2.39 \pm 1.87$ & $n s$ \\
\hline $\mathrm{MEP}_{(\mathrm{TS})}$ & $1.06 \pm 0.54$ & $1.35 \pm 0.49$ & $n s$ \\
\hline$I H I_{c \max }(m V)$ & $0.60 \pm 0.18$ & $0.59 \pm 0.21$ & ns \\
\hline $\mathrm{MEP}_{(\mathrm{CS})}$ & $1.73 \pm 1.26$ & $2.16 \pm 1.88$ & ns \\
\hline $\operatorname{MEP}_{(\mathrm{TS})}$ & $1.82 \pm 0.77$ & $1.79 \pm 1.10$ & $n s$ \\
\hline$I H I_{c \text { bef-mvt }}(m V)$ & $1.12 \pm 0.25^{*}$ & $0.80 \pm 0.23$ & $n s(0.06)$ \\
\hline $\mathrm{MEP}_{(\mathrm{CS})}$ & $1.89 \pm 1.18$ & $2.20 \pm 2.13$ & $n s$ \\
\hline $\mathrm{MEP}_{(\mathrm{TS})}$ & $1.99 \pm 0.82$ & $2.32 \pm 1.38$ & ns \\
\hline$I H I_{c \text { mvt-onset }}(m V)$ & $1.28 \pm 0.43^{*}$ & $0.85 \pm 0.21$ & $<0.02$ \\
\hline $\operatorname{MEP}_{(\mathrm{CS})}$ & $1.96 \pm 1.26$ & $2.74 \pm 2.19$ & $n s$ \\
\hline $\mathrm{MEP}_{(\mathrm{TS})}$ & $2.51 \pm 1.44$ & $3.33 \pm 1.69$ & $n s$ \\
\hline
\end{tabular}

* = $\mathrm{IHI}_{\mathrm{C}}$ significantly different from rest; $n s=$ non-significant. Note that 4 subjects were only tested for their left $(n=2)$ or right $(n=2)$ hand and statistics are therefore reported for the 9 subjects tested on both hands. 
Table 3. $\mathrm{IHI}_{\mathrm{i}}$ and MEP Amplitudes of CS and TS (Mean $\pm S D$ )

\begin{tabular}{|c|c|c|c|}
\hline \multirow[b]{2}{*}{$\begin{array}{l}\operatorname{IHI}_{i}\left[M E P_{(C S}+T S\right) / \\
\left.M E P_{(T S)}\right]\end{array}$} & \multicolumn{2}{|c|}{ Moving Hand } & \multirow[b]{2}{*}{$\begin{array}{c}p \text { Value } \\
\text { (Right/Left) }\end{array}$} \\
\hline & $\begin{array}{l}\text { Right Hand } \\
(n=11)\end{array}$ & $\begin{array}{l}\text { Left Hand } \\
(n=11)\end{array}$ & \\
\hline$I H I_{i \text { rest }}(m V)$ & $0.50 \pm 0.19$ & $0.53 \pm 0.20$ & ns \\
\hline $\operatorname{MEP}_{(\mathrm{CS})}$ & $1.37 \pm 1.03$ & $2.27 \pm 1.86$ & ns \\
\hline $\mathrm{MEP}_{(\mathrm{TS})}$ & $0.95 \pm 0.39$ & $1.10 \pm 0.44$ & $n s$ \\
\hline$I H I_{i \max }(m V)$ & $0.30 \pm 0.16 *$ & $0.40 \pm 0.20 *$ & ns \\
\hline $\mathrm{MEP}_{(\mathrm{CS})}$ & $1.65 \pm 1.56$ & $2.52 \pm 1.63$ & ns \\
\hline $\mathrm{MEP}_{(\mathrm{TS})}$ & $1.13 \pm 0.94$ & $1.46 \pm 0.85$ & ns \\
\hline$I H I_{i \text { bef-mvt }}(m V)$ & $0.54 \pm 0.30$ & $0.64 \pm 0.50$ & $n s$ \\
\hline $\mathrm{MEP}_{(\mathrm{CS})}$ & $2.26 \pm 1.22$ & $3.28 \pm 1.69$ & $n s$ \\
\hline $\operatorname{MEP}_{(\mathrm{TS})}$ & $0.94 \pm 0.60$ & $1.72 \pm 1.43$ & ns \\
\hline$I H I_{i \text { mvt-onset }}(m V)$ & $0.43 \pm 0.25$ & $0.57 \pm 0.32$ & ns \\
\hline $\operatorname{MEP}_{(\mathrm{CS})}$ & $2.62 \pm 1.17$ & $3.94 \pm 1.85$ & $n s$ \\
\hline $\operatorname{MEP}_{(\mathrm{TS})}$ & $1.06 \pm 0.68$ & $1.56 \pm 1.14$ & ns \\
\hline
\end{tabular}

$*=\mathrm{IHI}_{\mathrm{i}}$ significantly different from rest; $n s=$ non-significant. Note that 4 subjects were only tested for their left $(n=2)$ or right $(n=2)$ hand and statistics are therefore reported for the 9 subjects tested on both hands.

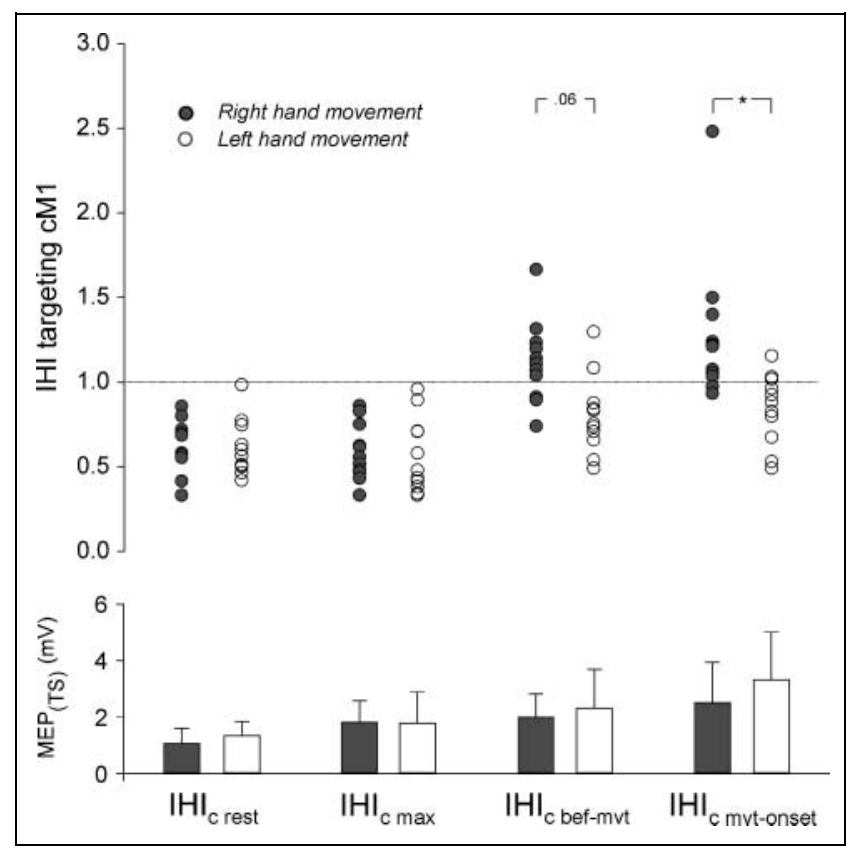

Figure 2. Individual values of $\mathrm{IHI}_{\mathrm{c}}$ rest and in the process of generation of voluntary index finger abduction motions with the right $(n=11)$ or left $(n=11)$ hand. Note that four subjects were only tested for their left $(n=2)$ or right $(n=2)$ hand, and statistics are therefore reported on the remaining nine subjects tested on both hands. $\mathrm{IHI}_{\mathrm{C} \max }$ depicts maximal inhibition soon after the go signal. $\mathrm{IHI}_{\mathrm{C} \text { max }}$ was comparable to $\mathrm{IHI}_{\mathrm{C}}$ rest with movements of both hands. In contrast, premovement $\mathrm{IHI}_{\mathrm{C} \text { bef-mvt }}$ and $\mathrm{IHI}_{\mathrm{c} \text { mvt-onset }}$ were more prominent with movements of the left than right hand $(p=.06$ and $p<.02$, respectively), in the presence of comparable $\mathrm{MEP}_{(\mathrm{TS})}$ amplitudes. movements of both hands, $\mathrm{IHI}_{\mathrm{c}}$ bef-mvt and $\mathrm{IHI}_{\mathrm{c}}$ mvt-onset were deeper with left than with right hand movements $(p=.06$ and $p<.02$, respectively, see Table 2 and Figure 2). $\mathrm{MEP}_{(\mathrm{TS})}$ and $\mathrm{MEP}_{(\mathrm{CS})}$ amplitudes were similar in left and right hands at any premovement timing (Figure 2, bottom).

\section{Modulation of Interhemispheric Inhibition Targeting the Primary Motor Cortex Ipsilateral to the Moving Hand}

$\mathrm{IHI}_{\mathrm{i}}$ conveys information on the IHI originating in cM1 and targeting iM1, the motor cortex controlling the resting hand. $\mathrm{IHI}_{\mathrm{i}} \max , \mathrm{IHI}_{\mathrm{i}}$ bef-mvt, and $\mathrm{IHI}_{\mathrm{i}}$ mvt-onset were measured $97 \pm 18.4,166 \pm 27.4$, and $163 \pm$ $29.3 \mathrm{msec}$, respectively, after the go signal for right hand movements and $99 \pm 29.5,164 \pm 27.2$, and $180 \pm$ $24.1 \mathrm{msec}$ for movements of the left hand (ANOVA, $n s)$. Premovement $\mathrm{IHI}_{\mathrm{i}}$ was characterized by a deep inhibition throughout movement preparation, which was indistinguishable for both hands (Figure 3). A twoway repeated measures ANOVA showed a significant main effect of timing $(F=6.4, p=.003)$ without interaction $(F=1.4, p=.3)$. $\mathrm{IHI}_{\mathrm{i} \max }$ was stronger when compared with rest or immediately preceding move-

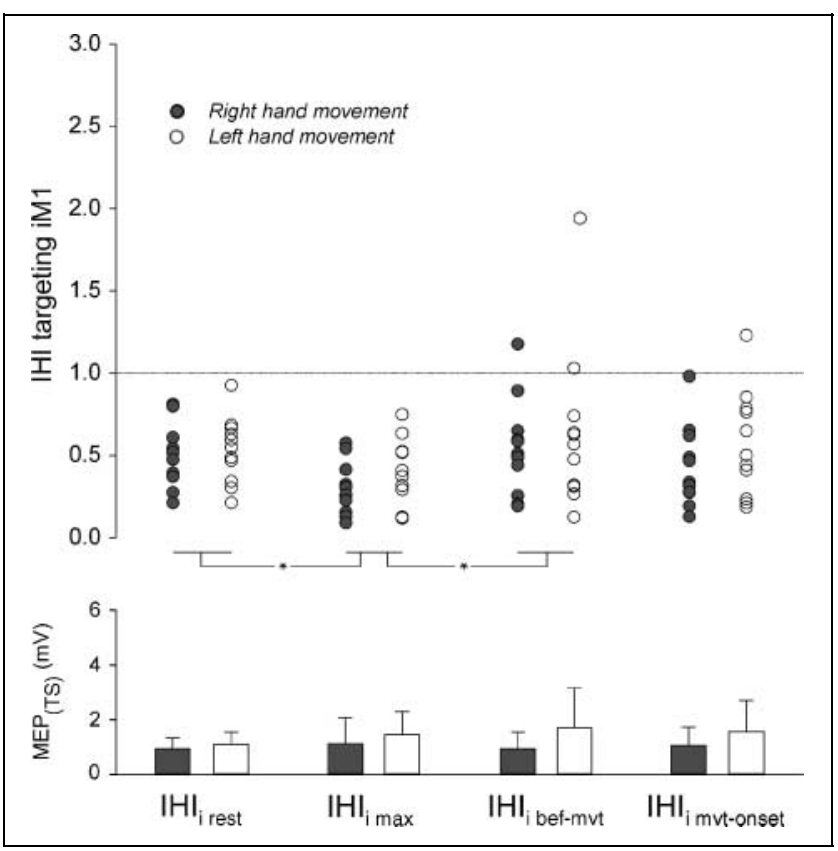

Figure 3. Individual values of $\mathrm{IHI}_{\mathrm{i}}$ rest and in the process of generation of voluntary index finger abduction motions with the right $(n=11)$ or left $(n=11)$ hand. Note that four subjects were only tested for their left $(n=2)$ or right $(n=2)$ hand and statistics are therefore reported on the remaining nine subjects tested on both hands. $\mathrm{IHI}_{\mathrm{i} \text { max }}$ depicts maximal inhibition soon after the go signal. $\mathrm{IHI}_{\mathrm{i} \text { max }}$ was deeper than $\mathrm{IHI}_{\mathrm{i}}$ rest or $\mathrm{IHI}_{\mathrm{i} \text { bef-mvt }}$ for movements of both hands of subjects $\left({ }^{*} p<.05\right)$. $\mathrm{IHI}_{\mathrm{i}}$ and the amplitude of $\mathrm{MEP}_{(\mathrm{TS})}$ (elicited by stimulation of iM1) were comparable in both hands of subjects at all premovement timings. 
ments $\left(\mathrm{IHI}_{\mathrm{c} \text { bef-mvt }}\right)$ of either hand (Table 3 and Figure 3, all $p<.05)$. $\mathrm{MEP}_{(\mathrm{TS})}$ and $\mathrm{MEP}_{(\mathrm{CS})}$ amplitudes were similar in left and right hands at any premovement timing (Figure 3).

\section{Shift in Interhemispheric Inhibition Balance}

Computing the difference between $\mathrm{IHI}_{\mathrm{i}}$ and $\mathrm{IHI}_{\mathrm{c}}\left(\mathrm{IHI}_{\mathrm{i}}-\mathrm{c}\right)$ evidenced the build-up of a progressive imbalance in IHI during movement preparation (Figure 4). As expected, $\mathrm{IHI}_{\mathrm{i}}$ - c was close to 0 at rest (comparable levels of $\mathrm{IHI}_{\mathrm{c} \text { rest }}$ and $\mathrm{IHI}_{\mathrm{i} \text { rest }}$ ). For right hand movements, $\mathrm{IHI}_{\mathrm{i}-\mathrm{c}}$ decreased monotonically during movement preparation, indicating a progressive shift in the IHI balance favoring inhibition of iM1 (deep $\mathrm{IHI}_{\mathrm{i}}$ ) over that of $\mathrm{cM} 1$ (released $\mathrm{IHI}_{\mathrm{c}}$ ) (Figure $4 \mathrm{~A}$ ), mainly because of a strong $\mathrm{IHI}_{\mathrm{i} \max }$ followed by a progressive release in $\mathrm{IHI}_{\mathrm{c}}$ bef-mvt

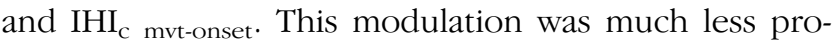
nounced for left hand movements disclosing a nearly constant balance between IHI exerted by each hemisphere during movement preparation (Figure 4B). Indeed, a two-way repeated measures ANOVA showed a significant main effect of timing $(F=9.4, p=.002)$ and a significant Moving Hand $\times$ Timing interaction $(F=$ $4.0, p=.026) . \mathrm{IHI}_{\mathrm{i}}-\mathrm{c}$ mvt-onset was significantly lower for right than left hand movements $(p=.03$, Figure 4$)$. No effect was found on $\mathrm{MEP}_{(\mathrm{TS}) \mathrm{i}-\mathrm{c}}$ indicating that the intermanual difference in $\mathrm{IHI}_{\mathrm{i}}-\mathrm{c}$ was not related to a similar difference in premovement corticospinal excitability.

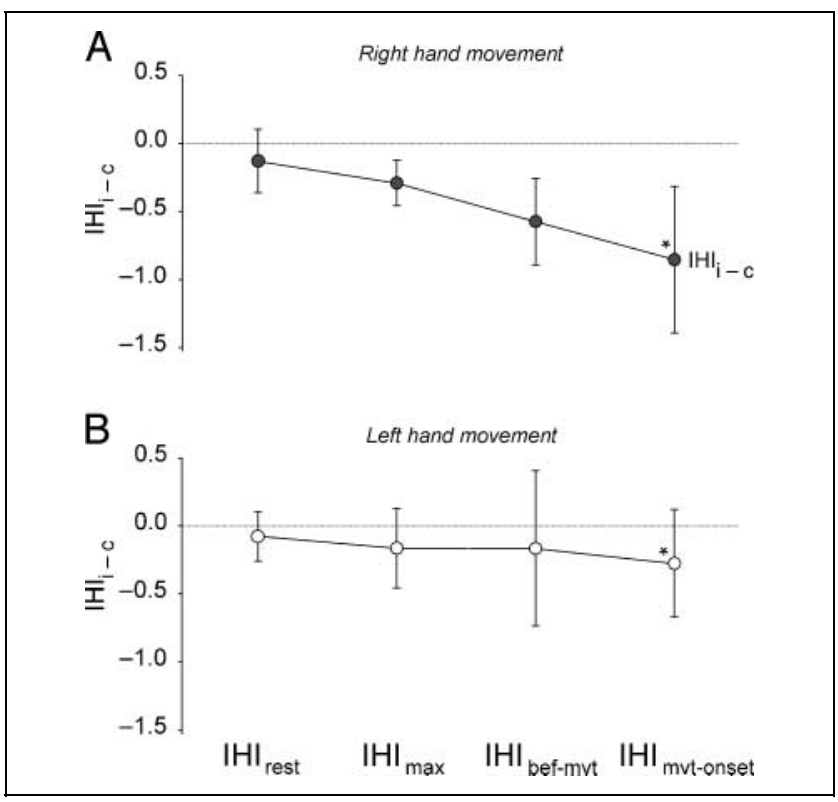

Figure 4. $\mathrm{IHI}_{\mathrm{i}-\mathrm{c}}$ is shown for each hand movement and conveys information on the overall modulation in IHI balance between both motor cortices. Note the value close to 0 at rest (balanced $\mathrm{IHI}_{\mathrm{C}}$ and $\mathrm{IHI}_{\mathrm{i}}$ ) and then the monotonic decrease in $\mathrm{IHI}_{\mathrm{i}}-\mathrm{c}$ with right hand movements only, suggesting a progressive reduction of $\mathrm{IHI}_{\mathrm{C}}$ with respect to $\mathrm{IHI}_{\mathrm{i}} \cdot{ }^{*} \mathrm{IHI}_{\mathrm{i}}$ - c mvt-onset was significantly lower for right than left hand movements $(p=.03)$.
Finally, we did not find any correlation between the age of the subjects and any of the IHI measurements performed in the present study.

\section{DISCUSSION}

Our results show a differential modulation of IHI with right and left hand movements in right-handed healthy human subjects. Common to right and left hand movements was the balanced IHI early in the premovement period and the deep $\mathrm{IHI}_{\mathrm{i}}$ throughout movement preparation, which could contribute to avoid mirroring during unilateral hand motions. However, closer to movement onset, right hand movements resulted in a much more prominent disinhibition of cM1 than left hand movements, possibly releasing motor cortical representations in the dominant hemisphere to a larger extent than in the nondominant hemisphere. As a consequence, movements of the right hand were associated with a progressive shift in the IHI balance favoring inhibition of iM1 (deep $\mathrm{IHI}_{\mathrm{i}}$ ) over that of cM1 (released $\mathrm{IHI}_{\mathrm{C}}$ ), whereas IHI modulation during left hand movements disclosed a nearly constant balance between the IHI exerted by each hemisphere. The differential modulation of IHI identified with right and left hand movements could contribute to the more accurate performance of skilled finger motions with the dominant hand (Triggs et al., 1997, 2000).

A frequent observation made in behavioral studies of manual dexterity is the superior skill of the right hand under a variety of motor conditions (Coren \& Porac, 1977). This right-hand performance advantage is particularly marked in tasks requiring rapid and/or very precise finger movements (Roy et al., 2003; Triggs et al., 1997, 2000; Todor \& Kyprie, 1980; Peters \& Durding, 1978). Approximately $90 \%$ of all subjects are right-handed (Coren \& Porac, 1977), but the neural bases of this human right handedness are poorly understood.

\section{Movement-related Interhemispheric Inhibition Targeting the Primary Motor Cortex Contralateral to the Moving Hand}

To our knowledge, our study is the first to reveal a difference in the way IHI is modulated with right and left hand movements in right-handed individuals. This IHI asymmetry appears to operate in association with performance of skilled movements but not during rest (De Gennaro et al., 2004; Salerno \& Georgesco, 1996; Meyer et al., 1995, 1998). The development of an IHI imbalance in this setting could provide the right hand with an important advantage in finger motor control. In fact, an appropriate release of inhibition in cM1 during movement preparation is thought to play a crucial role in shaping the motor command to the moving hand by ensuring the recruitment of a very precise set of muscles at the right timing (Davare, Duque, Vandermeeren, 
Thonnard, \& Olivier, in press; Murase et al., 2004; Sohn \& Hallett, 2004; Hallett, 2000, 2003, 2004). Inhibition is inappropriate in neurological disorders such as dystonia (Butefisch, Boroojerdi, Chen, Battaglia, \& Hallett, 2005; Sohn \& Hallett, 2004; Stinear \& Byblow, 2004a, 2004b), Parkinson's disease (Ridding, Inzelberg, \& Rothwell, 1995), or Tourette's syndrome (Ziemann, Tergau, Netz, \& Homberg, 1997) and may influence functional recovery of the paretic hand after stroke (Duque, Hummel, et al., 2005; Murase et al., 2004). In normal conditions, release of inhibition in cM1 has already been demonstrated in intracortical circuits immediately preceding (Reynolds \& Ashby, 1999) and during (Stinear \& Byblow, 2004a; Zoghi, Pearce, \& Nordstrom, 2003; Ridding, Taylor, \& Rothwell, 1995) selective activation of a right hand muscle. We propose that development of an IHI imbalance might also contribute to release cortical representations from inhibition in cM1 (see Figure 5) and therefore enable the subsequent excitatory drive to produce the intended movement (Floeter \& Rothwell, 1999). Then, it is conceivable that the stronger IHIc at left hand movement onset is responsible for the necessity to recruit more corticospinal neurons with left than right hand movements to achieve similar performance levels (Semmler \& Nordstrom, 1998; Ikoma, Samii, Mercuri, Wassermann, \& Hallett, 1996). It remains to be determined whether these intermanual differences in IHIc are a consequence of predefined asymmetries in human motor control or of the preferred (and more frequent) use of the right over the left hand. It is also possible that, rather than being responsible for asymmetries in manual dexterity, the intermanual difference in premovement IHIc represents a direct consequence of a more pronounced ipsilateral contribution, as shown for the left dorsal premotor cortex, to left hand movements
(Verstynen, Diedrichsen, Albert, Aparicio, \& Ivry, 2005; Haaland, Elsinger, Mayer, Durgerian, \& Rao, 2004; Cramer, Finklestein, Schaechter, Bush, \& Rosen, 1999; Kim, Ashe, Hendrich, et al., 1993). Although the subjects' age in this study did not correlate with intermanual differences in IHI, a larger sample would be required to specifically test this experimental hypothesis.

\section{Mechanisms Underlying Intermanual Differences in Movement-related Interhemispheric Inhibition Targeting the Contralateral Motor Cortex}

IHI is most likely mediated through transcallosal glutamatergic connections acting on local inhibitory interneurons in the contralateral motor cortex (Daskalakis et al., 2002; Berlucchi, 1966). Therefore, the level of IHI could theoretically depend on both the strength of the transcallosal excitatory input and the degree of intracortical inhibition. The respective contribution of these two processes to the intermanual difference in movementrelated IHI, and in particular to the persistently strong $\mathrm{IHI}_{\mathrm{C}}$ at the onset of left hand movements, is not clear. The left motor cortex is active during performance of left hand movements (to a larger extent than the right motor cortex with performance of right hand movements) (Verstynen et al., 2005; Ziemann \& Hallett, 2001; Leocani et al., 2000; Beltramello et al., 1998; Singh et al., 1998; Kim, Ashe, Georgopoulos, et al., 1993), and TMS over left M1 results in deleterious effects on left hand motor performance (Chen, Cohen, \& Hallett, 1997; Chen, Gerloff, Hallett, \& Cohen, 1997). It is then possible that left M1 activity during left hand movements leads to persistent $\mathrm{IHI}_{\mathrm{C}}$ over the right $\mathrm{M} 1$ and secondarily poorer motor performance of the left hand. Alternatively, there may be a persistently strong inhibitory activity
Figure 5. Schematic representation of $\mathrm{IHI}_{\mathrm{C}}$ and $\mathrm{IHI}_{\mathrm{i}}$ at onset of right and left hand movements. Note that right hand movements were associated with a much more prominent disinhibition of cM1 than left hand movements, resulting in an overall IHI imbalance favoring inhibition of iM1 over CM1 for right hand motions. This process might release muscles from inhibition in the cM1 while preventing the occurrence of mirror activity in iM1 and could therefore provide an important gain for the control of dexterous movements of the right dominant hand. $\mathrm{IHI}_{\mathrm{C}}=\mathrm{IHI}$ targeting $\mathrm{cM} 1$; $\mathrm{IHI}_{\mathrm{i}}=\mathrm{IHI}$ targeting $\mathrm{iM} 1$.

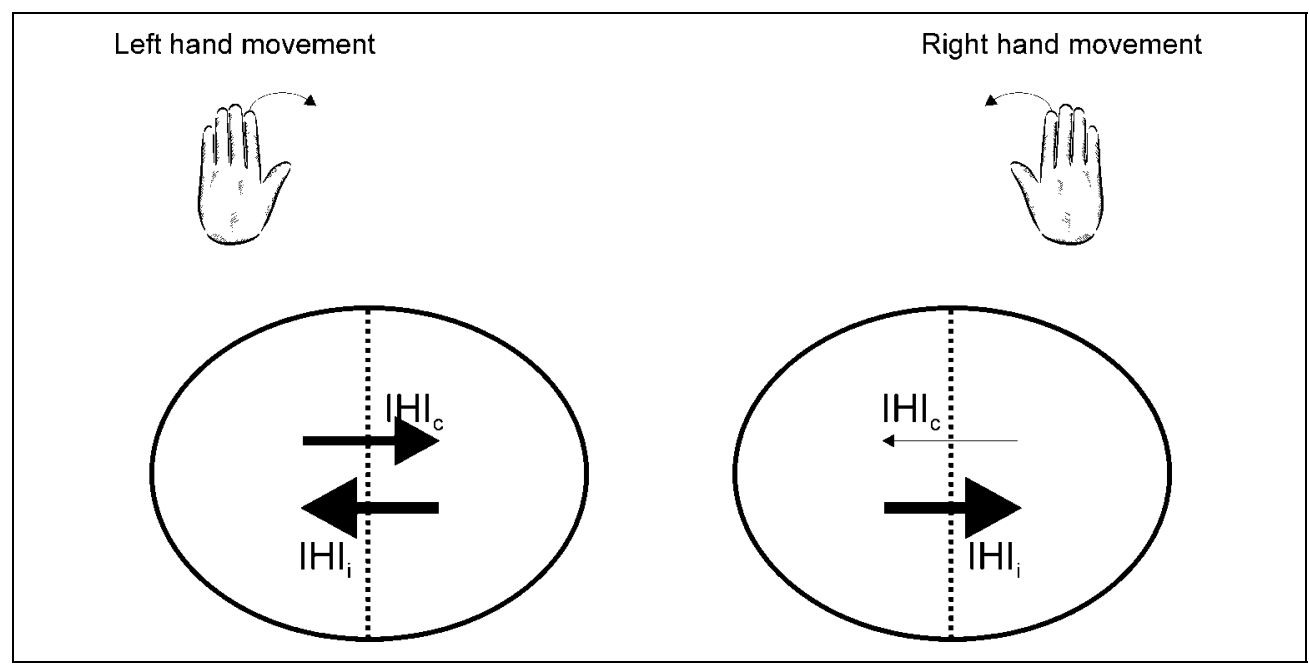


within the right M1 when generating a left hand movement (Garry, Kamen, \& Nordstrom, 2004). This higher interneuronal inhibitory activity within the right M1 could prevent it from being released from $\mathrm{IHI}_{\mathrm{C}}$ (Chen, 2004; Ilic, Jung, \& Ziemann, 2004; Daskalakis et al., 2002; Banich \& Brown, 2000; Priori et al., 1999; Cicinelli, Traversa, Bassi, Scivoletto, \& Rossini, 1997; Triggs, Calvanio, Macdonell, Cros, \& Chiappa, 1994; Berardelli, Inghilleri, Cruccu, Mercuri, \& Manfredi, 1991). It is of note that although there is substantial evidence that IHI is mediated through transcallosal connections (Daskalakis et al., 2002; Di Lazzaro et al., 1999; Meyer et al., 1995, 1998), some subcortical mechanisms might also be involved (Gerloff et al., 1998) and therefore contribute to some extent to the intermanual difference in movement-related $\mathrm{IHI}_{\mathrm{C}}$ evidenced in the present study.

\section{Movement-related Interhemispheric Inhibition Targeting Primary Motor Cortex Ipsilateral to the Moving Hand}

The finding of comparable inhibition of iM1 for movements of both hands suggests that the higher incidence of mirroring with left than right hand movements (Liepert, Dettmers, Terborg, \& Weiller, 2001; Armatas, Summers, \& Bradshaw, 1994; Todor \& Lazarus, 1986) cannot be accounted for by a differential efficiency of IHIi. Rather, more frequent mirroring with left hand movements might relate to an increased contribution of the ipsilateral left premotor cortex when movements are performed with the nondominant hand (Verstynen et al., 2005; Haaland et al., 2004; Cramer et al., 1999; Kim, Ashe, Hendrich, et al., 1993). A higher recruitment of corticospinal neurons with nondominant hand movements (Semmler \& Nordstrom, 1998; Ikoma et al., 1996) could also lead to an interhemispheric spread of facilitation to the ipsilateral M1 (Baumer et al., 2006; Hanajima et al., 2001) and therefore elicit mirroring. Alternatively, the absence of movement-related modulation of IHI might alter the degree of intermanual independence required to perform unilateral hand movements. In fact, because the default mode of activation of the central nervous system seems to favor execution of mirror movements (Swinnen, 2002; Serrien, Bogaerts, Suy, \& Swinnen, 1999), it is possible that the ability to execute strictly unilateral movements relies on an adequate movement-related modulation of IHI between homonymous movement representations (Duque, Mazzocchio, et al., 2005; Liepert et al., 2001; Leocani et al., 2000; Chiarello \& Maxfield, 1996; Schnitzler et al., 1996).

\section{Conclusion}

In conclusion, our results demonstrate a more prominent shift, from a balanced IHI at rest to an IHI predominantly directed toward the ipsilateral M1, with right than left hand movements. Such movement-related modulation of IHI might release movements performed with the right hand from inhibition while preventing the occurrence of mirror activity in the left hand, and could therefore provide an important gain for the control of dexterous movements of the dominant hand (Triggs et al., 1997, 2000).

\section{Acknowledgments}

J. Duque is a research assistant at the Belgian National Funds for Scientific Research (FNRS). P. Celnik is supported by a grant from the Rehabilitation Medicine Scientist Training Program (RMSTP Grant 5K12HD001097). F. Hummel is supported by a grant of Alexander v. Humboldt-Foundation (FeodorLynen). This work was supported by the Intramural Research Program of the National Institute of Neurological Disorders and Stroke, National Institutes of Health.

Reprint requests should be sent to Leonardo G. Cohen, Human Cortical Physiology Section, National Institute of Neurological Disorders and Stroke, National Institutes of Health, Bethesda, MD 20817, or via e-mail: cohenl@ninds.nih.gov.

\section{REFERENCES}

Aboitiz, F., \& Montiel, J. (2003). One hundred million years of interhemispheric communication: The history of the corpus callosum. Brazilian Journal of Medical and Biological Research, 36, 409-420.

Armatas, C. A., Summers, J. J., \& Bradshaw, J. L. (1994). Mirror movements in normal adult subjects. Journal of Clinical and Experimental Neuropsychology, 16, 405-413.

Banich, M. T., \& Brown, W. S. (2000). A life-span perspective on interaction between the cerebral hemispheres. Developmental Neuropsychology, 18, 1-10.

Baumer, T., Bock, F., Koch, G., Lange, R., Rothwell, J. C., Siebner, H. R., et al. (2006). Magnetic stimulation of human premotor or motor cortex produces interhemispheric facilitation through distinct pathways. Journal of Physiology, 572, 857-868.

Beltramello, A., Cerini, R., Puppini, G., El-Dalati, G., Viola, S., Martone, E., et al. (1998). Motor representation of the hand in the human cortex: An f-MRI study with a conventional $1.5 \mathrm{~T}$ clinical unit. Italian Journal of Neurological Sciences, 19, 277-284.

Berardelli, A., Inghilleri, M., Cruccu, G., Mercuri, B., \& Manfredi, M. (1991). Electrical and magnetic transcranial stimulation in patients with corticospinal damage due to stroke or motor neurone disease. Electroencephalography and Clinical Neurophysiology, 81, 389-396.

Berlucchi, G. (1966). Electroencephalographic studies in "split brain" cats. Electroencephalography and Clinical Neurophysiology, 20, 348-356.

Boroojerdi, B., Diefenbach, K., \& Ferbert, A. (1996). Transcallosal inhibition in cortical and subcortical cerebral vascular lesions. Journal of Neurological Sciences, 144, 160-170.

Butefisch, C. M., Boroojerdi, B., Chen, R., Battaglia, F., \& Hallett, M. (2005). Task-dependent intracortical inhibition is impaired in focal hand dystonia. Movement Disorders, 20, 545-551.

Chen, R. (2004). Interactions between inhibitory and excitatory circuits in the human motor cortex. Brain Research, Experimental Brain Research, 154, 1-10. 
Chen, R., Cohen, L. G., \& Hallett, M. (1997). Role of the ipsilateral motor cortex in voluntary movement. Canadian Journal of Neurological Sciences, 24, 284-291.

Chen, R., Gerloff, C., Hallett, M., \& Cohen, L. G. (1997). Involvement of the ipsilateral motor cortex in finger movements of different complexities. Annals of Neurology, 41, 247-254.

Chiarello, C., \& Maxfield, L. (1996). Varieties of interhemispheric inhibition, or how to keep a good hemisphere down. Brain and Cognition, 30, 81-108.

Cicinelli, P., Traversa, R., Bassi, A., Scivoletto, G., \& Rossini, P. M. (1997). Interhemispheric differences of hand muscle representation in human motor cortex. Muscle and Nerve, 20, 535-542.

Coren, S., \& Porac, C. (1977). Fifty centuries of righthandedness: The historical record. Science, 198, 631-632.

Cramer, S. C., Finklestein, S. P., Schaechter, J. D., Bush, G., \& Rosen, B. R. (1999). Activation of distinct motor cortex regions during ipsilateral and contralateral finger movements. Journal of Neurophysiology, 81, 383-387.

Daskalakis, Z. J., Christensen, B. K., Fitzgerald, P. B., Roshan, L., \& Chen, R. (2002). The mechanisms of interhemispheric inhibition in the human motor cortex. Journal of Physiology, 543, 317-326.

Davare, M., Duque, J., Vandermeeren, Y., Thonnard, J. L., \& Olivier, E. (in press). Role of the ipsilateral primary motor cortex in controlling the timing of hand muscle recruitment. Cerebral Cortex.

De Gennaro, L., Bertini, M., Pauri, F., Cristiani, R., Curcio, G., Ferrara, M., et al. (2004). Callosal effects of transcranial magnetic stimulation (TMS): The influence of gender and stimulus parameters. Neuroscience Research, 48, 129-137.

Di Lazzaro, V., Oliviero, A., Profice, P., Insola, A., Mazzone, P., Tonali, P., et al. (1999). Direct demonstration of interhemispheric inhibition of the human motor cortex produced by transcranial magnetic stimulation. Brain Research, Experimental Brain Research, 124, 520-524.

Duque, J., Hummel, F., Celnik, P., Murase, N., Mazzocchio, R., \& Cohen, L. G. (2005). Transcallosal inhibition in chronic subcortical stroke. Neuroimage, 28, 940-946.

Duque, J., Mazzocchio, R., Dambrosia, J., Murase, N., Olivier, E., \& Cohen, L. G. (2005). Kinematically specific interhemispheric inhibition operating in the process of generation of a voluntary movement. Cerebral Cortex, 15, 588-593.

Ferbert, A., Priori, A., Rothwell, J. C., Day, B. L., Colebatch, J. G., \& Marsden, C. D. (1992). Interhemispheric inhibition of the human motor cortex. Journal of Physiology, 453, $525-546$.

Floeter, M. K., \& Rothwell, J. C. (1999). Releasing the brakes before pressing the gas pedal. Neurology, 53, 664-665.

Garry, M. I., Kamen, G., \& Nordstrom, M. A. (2004). Hemispheric differences in the relationship between corticomotor excitability changes following a fine-motor task and motor learning. Journal of Neurophysiology, 91, 1570-1578.

Gerloff, C., Cohen, L. G., Floeter, M. K., Chen, R., Corwell, B., \& Hallett, M. (1998). Inhibitory influence of the ipsilateral motor cortex on responses to stimulation of the human cortex and pyramidal tract. Journal of Physiology, 510, 249-259.

Haaland, K. Y., Elsinger, C. L., Mayer, A. R., Durgerian, S., \& Rao, S. M. (2004). Motor sequence complexity and performing hand produce differential patterns of hemispheric lateralization. Journal of Cognitive Neuroscience, 16, 621-636.
Hallett, M. (2000). Disorder of movement preparation in dystonia. Brain, 123, 1765-1766.

Hallett, M. (2003). Surround inhibition. Supplements to Clinical Neurophysiology, 56, 153-159.

Hallett, M. (2004). Dystonia: Abnormal movements result from loss of inhibition. Advances in Neurology, 94, 1-9.

Hanajima, R., Ugawa, Y., Machii, K., Mochizuki, H., Terao, Y., Enomoto, H., et al. (2001). Interhemispheric facilitation of the hand motor area in humans. Journal of Physiology, 531, 849-859.

Ikoma, K., Samii, A., Mercuri, B., Wassermann, E. M., \& Hallett, M. (1996). Abnormal cortical motor excitability in dystonia. Neurology, 46, 1371-1376.

Ilic, T. V., Jung, P., \& Ziemann, U. (2004). Subtle hemispheric asymmetry of motor cortical inhibitory tone. Clinical Neurophysiology, 115, 330-340.

Kaelin-Lang, A., \& Cohen, L. G. (2000). Enhancing the quality of studies using transcranial magnetic and electrical stimulation with a new computer-controlled system. Journal of Neuroscience Methods, 102, 81-89.

Kim, S. G., Ashe, J., Georgopoulos, A. P., Merkle, H., Ellermann, J. M., Menon, R. S., et al. (1993). Functional imaging of human motor cortex at high magnetic field. Journal of Neurophysiology, 69, 297-302.

Kim, S. G., Ashe, J., Hendrich, K., Ellermann, J. M., Merkle, H., Ugurbil, K., et al. (1993). Functional magnetic resonance imaging of motor cortex: Hemispheric asymmetry and handedness. Science, 261, 615-617.

Kim, Y. H., Jang, S. H., Chang, Y., Byun, W. M., Son, S., \& Ahn, S. H. (2003). Bilateral primary sensori-motor cortex activation of post-stroke mirror movements: An fMRI study. NeuroReport, 14, 1329-1332.

Leocani, L., Cohen, L. G., Wassermann, E. M., Ikoma, K., \& Hallett, M. (2000). Human corticospinal excitability evaluated with transcranial magnetic stimulation during different reaction time paradigms. Brain, 123, 1161-1173.

Liepert, J., Dettmers, C., Terborg, C., \& Weiller, C. (2001). Inhibition of ipsilateral motor cortex during phasic generation of low force. Clinical Neurophysiology, 112, 114-121.

Meyer, B. U., Roricht, S., Grafin von Einsiedel, H., Kruggel, F., \& Weindl, A. (1995). Inhibitory and excitatory interhemispheric transfers between motor cortical areas in normal humans and patients with abnormalities of the corpus callosum. Brain, 118, 429-440.

Meyer, B. U., Roricht, S., \& Woiciechowsky, C. (1998). Topography of fibers in the human corpus callosum mediating interhemispheric inhibition between the motor cortices. Annals of Neurology, 43, 360-369.

Murase, N., Duque, J., Mazzocchio, R., \& Cohen, L. G. (2004). Influence of interhemispheric interactions on motor function in chronic stroke. Annals of Neurology, 55, 400-409.

Netz, J. (1999). Asymmetry in transcallosal inhibition. Electroencephalography and Clinical Neurophysiology. Supplement, 51, 137-144.

Netz, J., Ziemann, U., \& Homberg, V. (1995). Hemispheric asymmetry of transcallosal inhibition in man. Brain Research, Experimental Brain Research, 104, 527-533.

Oldfield, R. C. (1971). The assessment and analysis of handedness: The Edinburgh inventory. Neuropsychologia, 9, 97-113

Peters, M., \& Durding, B. M. (1978). Handedness measured by finger tapping: A continuous variable. Canadian Journal of Psychology, 32, 257-261.

Priori, A., Oliviero, A., Donati, E., Callea, L., Bertolasi, L., \& Rothwell, J. C. (1999). Human handedness and asymmetry of the motor cortical silent period. Brain Research, Experimental Brain Research, 128, 390-396. 
Reynolds, C., \& Ashby, P. (1999). Inhibition in the human motor cortex is reduced just before a voluntary contraction. Neurology, 53, 730-735.

Ridding, M. C, Inzelberg, R., \& Rothwell, J. C. (1995). Changes in excitability of motor cortical circuitry in patients with Parkinson's disease. Annals of Neurology, 37, 181-188.

Ridding, M. C., Taylor, J. L., \& Rothwell, J. C. (1995). The effect of voluntary contraction on cortico-cortical inhibition in human motor cortex. Journal of Physiology, 487, 541-548.

Rossini, P. M., Barker, A. T., Berardelli, A., Caramia, M. D., Caruso, G., Cracco, R. Q., et al. (1994). Non-invasive electrical and magnetic stimulation of the brain, spinal cord and roots: Basic principles and procedures for routine clinical application. Report of an IFCN committee. Electroencephalography and Clinical Neurophysiology, 91, 79-92.

Rouiller, E. M., Babalian, A., Kazennikov, O., Moret, V., Yu, X. H., \& Wiesendanger, M. (1994). Transcallosal connections of the distal forelimb representations of the primary and supplementary motor cortical areas in macaque monkeys. Brain Research, Experimental Brain Research, 102, 227-243.

Roy, E. A., Bryden, P., \& Cavill, S. (2003). Hand differences in pegboard performance through development. Brain and Cognition, 53, 315-317.

Sakai, K., Ugawa, Y., Terao, Y., Hanajima, R., Furubayashi, T., \& Kanazawa, I. (1997). Preferential activation of different I waves by transcranial magnetic stimulation with a figure-of-eight-shaped coil. Brain Research, Experimental Brain Research, 113, 24-32.

Salerno, A., \& Georgesco, M. (1996). Interhemispheric facilitation and inhibition studied in man with double magnetic stimulation. Electroencephalography and Clinical Neurophysiology, 101, 395-403.

Schnitzler, A., Kessler, K. R., \& Benecke, R. (1996). Transcallosally mediated inhibition of interneurons within human primary motor cortex. Brain Research, Experimental Brain Research, 112, 381-391.

Semmler, J. G., \& Nordstrom, M. A. (1998). Hemispheric differences in motor cortex excitability during a simple index finger abduction task in humans. Journal of Neurophysiology, 79, 1246-1254.

Serrien, D. J., Bogaerts, H., Suy, E., \& Swinnen, S. P. (1999). The identification of coordination constraints across planes of motion. Brain Research, Experimental Brain Research, 128, 250-255.

Singh, L. N., Higano, S., Takahashi, S., Kurihara, N., Furuta, S., Tamura, H., et al. (1998). Comparison of ipsilateral activation between right and left handers: A functional MR imaging study. NeuroReport, 9, 1861-1866.

Sohn, Y. H., \& Hallett, M. (2004). Disturbed surround inhibition in focal hand dystonia. Annals of Neurology, 56, 595-599.

Stinear, C. M., \& Byblow, W. D. (2004a). Impaired modulation of intracortical inhibition in focal hand dystonia. Cerebral Cortex, 14, 555-561.
Stinear, C. M., \& Byblow, W. D. (2004b). Elevated threshold for intracortical inhibition in focal hand dystonia. Movement Disorders, 19, 1312-1317.

Swinnen, S. P. (2002). Intermanual coordination: From behavioural principles to neural-network interactions. Nature Reviews Neuroscience, 3, 348-359.

Swinnen, S. P., Dounskaia, N., \& Duysens, J. (2002). Patterns of bimanual interference reveal movement encoding within a radial egocentric reference frame. Journal of Cognitive Neuroscience, 14, 463-471.

Thut, G., Halsband, U., Regard, M., Mayer, E., Leenders, K. L., \& Landis, T. (1997). What is the role of the corpus callosum in intermanual transfer of motor skills? A study of three cases with callosal pathology. Brain Research, Experimental Brain Research, 113, 365-370.

Todor, J. I., \& Kyprie, P. M. (1980). Hand differences in the rate and variability of rapid tapping. Journal of Motor Behavior, 12, 57-62.

Todor, J. I., \& Lazarus, J. A. (1986). Exertion level and the intensity of associated movements. Developmental Medicine and Child Neurology, 28, 205-212.

Triggs, W. J., Calvanio, R., \& Levine, M. (1997). Transcranial magnetic stimulation reveals a hemispheric asymmetry correlate of intermanual differences in motor performance. Neuropsychologia, 35, 1355-1363.

Triggs, W. J., Calvanio, R., Levine, M., Heaton, R. K., \& Heilman, K. M. (2000). Predicting hand preference with performance on motor tasks. Cortex, 36, 679-689.

Triggs, W. J., Calvanio, R., Macdonell, R. A., Cros, D., \& Chiappa, K. H. (1994). Physiological motor asymmetry in human handedness: Evidence from transcranial magnetic stimulation. Brain Research, Experimental Brain Research, 636, 270-276.

Verstynen, T., Diedrichsen, J., Albert, N., Aparicio, P., \& Ivry, R. B. (2005). Ipsilateral motor cortex activity during unimanual hand movements relates to task complexity. Journal of Neurophysiology, 93, 1209-1222.

Werhahn, K. J., Fong, J. K., Meyer, B. U., Priori, A., Rothwell, J. C., Day, B. L., et al. (1994). The effect of magnetic coil orientation on the latency of surface EMG and single motor unit responses in the first dorsal interosseous muscle. Electroencephalography and Clinical Neurophysiology, 93, 138-146.

Ziemann, U., \& Hallett, M. (2001). Hemispheric asymmetry of ipsilateral motor cortex activation during unimanual motor tasks: Further evidence for motor dominance. Clinical Neurophysiology, 112, 107-113.

Ziemann, U., Tergau, F., Netz, J., \& Homberg, V. (1997). Delay in simple reaction time after focal transcranial magnetic stimulation of the human brain occurs at the final motor output stage. Brain Research, Experimental Brain Research, 744, 32-40.

Zoghi, M., Pearce, S. L., \& Nordstrom, M. A. (2003). Differential modulation of intracortical inhibition in human motor cortex during selective activation of an intrinsic hand muscle. Journal of Physiology, 550, 933-946. 